\title{
Desenvolvimento folicular de embriões de frangos de corte de diferentes genótipos expos- tos ao estresse térmico crônico
}

\author{
Folicular development of chicken broiler embryos of different genotypes, exposed \\ to chronic thermal stress
}

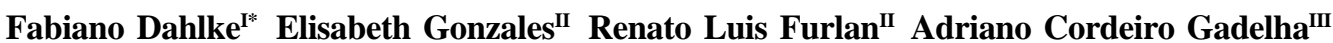 \\ Paulo Sérgio Rosa ${ }^{\mathrm{IV}}$ Régis Fernando Pastorelo Meurer ${ }^{\mathrm{I}}$ Alex Maiorka ${ }^{\mathrm{I}}$
}

\section{RESUMO}

O objetivo do trabalho foi avaliar as alterações tegumentares (morfogênese da pena), em embriões de frangos de corte de linhagens de diferentes padrões de crescimento, obtidos de ovos incubados sob diferentes temperaturas. Os ovos foram obtidos de matrizes das linhagens Cobb 500 e ISA JA57, distribuidos proporcionalmente em três incubadoras. Do primeiro (D1) ao sexto dia (D6) de incubação, utilizou-se uma temperatura padrão $\left(37,8^{\circ} \mathrm{C}\right)$. A partir do sétimo dia (D7) e até o momento do nascimento aos 21 dias (D21), uma das incubadoras teve a temperatura reduzida para $36,8^{\circ} \mathrm{C}$ (fria) e uma outra alterada para $38,8^{\circ} \mathrm{C}$ (quente). A terceira incubadora foi mantida a $37,8^{\circ} \mathrm{C}$ (controle). O delineamento adotado foi o inteiramente casualizado, em esquema fatorial $3 \times 2$ (temperatura de incubação e linhagem). A temperatura de incubação e a linhagem não alteraram a densidade dos folículos da pena (número médio de folículos por área de $337,5 \mu^{2}$ ) nas regiões femural e dorsopélvica dos embriões até os 11 dias (D11). Entretanto, observou-se aumento na densidade folicular na região dorsal dos embriões aos 16 dias (D16) devido ao aumento da temperatura, permanecendo até o momento do nascimento. É possivel oncluirque embriões incubados em temperatura acima da recomendada $\left(38,8^{\circ} \mathrm{C}\right)$ apresentam uma maior densidade de foliculos na região dorsopélvica. Apesar disso, a morfogênese dos folículos permaneceu inalterada.

Palavras-chave: desenvolvimento embrionário, empenamento, temperatura de incubação.

\section{ABSTRACT}

The objective of this research was to evaluate the tegument modification (feather morphogenesis) in embryos of broiler chicken, of different growth standard breeder lines, obtained from eggs incubated under different temperatures. Eggs of Cobb 500 and ISA JA57 breeders lines, were proportionally distributed in three incubators. From the first (D1) to the sixth day (D6) of incubation, temperature was maintained standard at $37.8^{\circ} \mathrm{C}$. From the seventh day (D7) until the moment of the birth on the twenty one days (D21), temperature was reduced to $36.8^{\circ} \mathrm{C}$ (Cold) in one of the incubators, and in another incubator was increased to $38.8^{\circ} \mathrm{C}$ (Hot). The temperature in the third incubator was maintained at $37.8^{\circ} \mathrm{C}$ (Control). It was used a completely randomized design with factorial $3 \times 2$ (temperature of incubation and breeder lines). Incubation temperature and breeder factor do not modify the follicular density of the feather (average number of follicles per area of $337.5 \mu^{2}$ in the femoral and dorsal tract of until eleven days (D11) embryos. An increase of follicular density in the dorsal region of sixteen days (D16) embryos was observed, because the temperature increased, of the remaining until the moment of birth, demonstrating that embryos incubated above the recommended temperature $\left(38.8^{\circ} \mathrm{C}\right)$ present higher follicles density in the dorsal tract. However, follicles morphogenesis remained unaltered.

Key words: embryonic development, feathering, hatch temperature.

\section{INTRODUÇÃO}

O processo de incubação é dependente de fatores físicos, como a temperatura, a umidade relativa, a viragem dos ovos, a ventilação (DECUYPERE \& MICHELS,1992; LEANDRO et al., 2000) e fatores

IDepartamento de Zootecnia, Universidade Federal do Paraná (UFPR). Rua dos Funcionários, 1540, 80035-050, Curitiba, PR, Brasil. E-mail: fdahlke@ufpr.br.*Autor para correspondência.

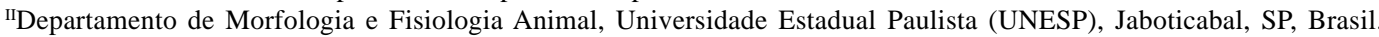

IIIDepartamento de Zootecnia, Universidade Federal do Ceará (UFC), Fortaleza, CE, Brasil.

${ }^{\mathrm{IV}}$ Centro Nacional de Pesquisa em Suínos e Aves, EMBRAPA, Concórdia, SC, Brasil. 
fisiológicos (THOMMES, 1987; TONA et al., 2003). Entre os fatores físicos, o de maior importância na determinação do bom desenvolvimento embrionário é a temperatura de incubação. BAROTT (1937) já revelava que $37,8^{\circ} \mathrm{C}$ seria a temperatura ótima para se obter melhor eclosão. A exposição do embrião a altas ou baixas temperaturas durante o período de incubação tem diferentes efeitos sobre o seu desenvolvimento e seu mecanismo fisiológico é afetado em muitos aspectos. Por exemplo, temperaturas extremas de $39^{\circ} \mathrm{C}$ ou $30^{\circ} \mathrm{C}$, por períodos constantes, são letais para os embriões (DECUYPERE \& MICHELS, 1992). Variações de menor intensidade, abaixo ou acima de $37,8^{\circ} \mathrm{C}$, podem acelerar ou retardar o desenvolvimento do embrião (LANCASTER \& JONES, 1988; LEANDRO et al., 2000).

Alguns trabalhos foram realizados na área de genética, por meio da introgressão do gene pescoço pelado $(\mathrm{Na})$ em linhagens de frangos de corte para aumentar a resistência ao calor, devido ao fato de esse gene promover uma redução do empenamento, principalmente na região do pescoço, resultando em uma maior habilidade em dissipar calor por meio das áreas superficiais expostas (DEEB \& CAHANER, 1999).

O processo de empenamento envolve complexos mecanismos influenciados por fatores nutricionais, hormonais, genéticos e ambientais e pela interação entre eles. Porém, vale ressaltar que o empenamento é determinado durante o período embrionário. Embora as penas possam apresentar diferentes características e diferentes formas durante as diversas fases da vida da ave, cada pena será originária de um folículo e de uma papila localizada em sua base. As sucessivas gerações de pena crescem a partir das papilas formadas durante a fase pré-natal. Dessa forma, pode-se dizer que o número de penas de uma ave adulta corresponde ao número de folículos formados no embrião (FURLAN \& MACARI, 2002).

As trocas de oxigênio e $\mathrm{CO}_{2}$ e o balanço hormonal, principalmente da Triiodotironina $\left(\mathrm{T}_{3}\right)$, Tiroxina $\left(\mathrm{T}_{4}\right)$ e Corticosterona, são os fatores fisiológicos de fundamental importância para o desenvolvimento embrionário (TULLETT, 1990; TONA et al., 2003). As trocas gasosas dependem da taxa de ventilação durante a incubação e das características do ovo, como a qualidade da casca e a viscosidade do albúmen. Quando a temperatura de incubação é menor que a recomendada, a partir do $17^{0}$ dia, há uma diminuição significativa nos níveis plasmáticos de $\mathrm{T}_{3} \mathrm{e}$ $\mathrm{T}_{4}$ no período pré-natal, com retardo na bicagem (DECUYPERE et al., 1981). Já quando o tempo de incubação é aumentado, há um aumento na concentração de $\mathrm{T}_{3}$ plasmático do embrião (OCKLEFORD et al., 1983), melhorando a condutância da casca e aumentando a eclodibilidade dos ovos (CHRISTENSEN et al., 1991).

Os hormônios da tireóide são considerados como os mais importantes no controle do crescimento e do desenvolvimento das diversas estruturas corporais (LAWRENCE \& FOLLER, 1997; GIACHETTO, 1998). O aumento nos níveis deste hormônio pode acelerar os diversos mecanismos de controle do crescimento e o desenvolvimento de um grande número de órgãos, como o cérebro e o fígado, e a estrutura esquelética, além de estimular o crescimento da cartilagem, aumentando seu peso. Esta variação hormonal também aumenta a síntese protéica, auxiliando a incorporação de aminoácidos sulfurados (DEUCHAR, 1952). SPERMAN (1971) demonstrou que as células do folículo da pena crescem sob ação direta dos hormônios $\mathrm{T}_{3}$ e $\mathrm{T}_{4}$. Dessa forma, pode-se especular a existência de alterações na formação do folículo, que se inicia no final da primeira semana, com a invaginação da epiderme para a derme subjacente, que pode ser provocada por alterações hormonais.

Assim, o objetivo do presente trabalho foi testar a hipótese de que o estresse térmico crônico por frio ou calor, durante a incubação, possa modificar a morfogênese da pena em frangos de corte portadores do gene $\mathrm{Na}$, ou do gene nana para a característica de empenamento.

\section{MATERIAL E MÉTODOS}

Foram utilizados 900 ovos fertilizados de uma linhagem de frango de corte de crescimento lento, homozigota dominante para o gene $\mathrm{NaNa}$ (ISA JA 57), com peso médio de 63,19g, oriundos de matrizes de 43 semanas de idade. Também foram utilizados 900 ovos férteis de uma linhagem híbrida comercial de frango de corte de rápido crescimento (Cobb $500^{\circledR}$ ), com peso médio de 62,75g, também oriundos de matrizes de 43 semanas de idade. Os ovos foram identificados e pesados individualmente antes de serem distribuídos proporcionalmente em três incubadoras ${ }^{1}$ com capacidade para 600 ovos cada, mantidas com temperatura de $37,8^{\circ} \mathrm{C}$ do $1^{\circ}$ (D1) ao $6^{\circ}$ dia (D6) de incubação. A partir do sétimo dia (D7) e até o nascimento aos 21 dias (D21), uma das incubadoras teve a temperatura reduzida para $36,8^{\circ} \mathrm{C}$ (temperatura fria - TF), outra alterada para $38,8^{\circ} \mathrm{C}$ (temperatura quente - TQ) e a terceira mantida a $37,8^{\circ} \mathrm{C}$ (controle - C).

Nos dias oito, nove, 10, 11, 12 e 16 e logo após o nascimento, foram selecionados 10 embriões de cada tratamento, provenientes de ovos de mesmo peso, para a análise de microscopia de luz (avaliação dos folículos). Nos D11, D16 e ao nascimento, também 
foram utilizados 10 embriões por tratamento, também oriundos de ovos com mesmas características, para microscopia de varredura para análise de densidade folicular. Cada embrião constituiu uma repetição para cada tratamento.

As coletas foram constituídas por amostras de pele das pterilosis dorsopélvica (dorso) e femural (perna). Para a microscopia de luz, após a coleta, os fragmentos do dorso e da perna dos embriões foram imediatamente fixados em solução de Bouim. Após a lavagem em álcool 50, contendo duas a três gotas de hidróxido de amônia para a retirada do fixador, os fragmentos foram desidratados em série crescentes de etanol, diafanizados em xilol e incluídos em parafina. De cada fragmento, foram obtidas 14 secções (semiseriadas) de $5 \mu \mathrm{m}$ de espessura, as quais foram coradas em Tricrômio de Masson e montadas com bálsamo do Canadá. Também foram coletados fragmentos das regiões dorsopélvica e femural para a análise de microscopia eletrônica de varredura ${ }^{2}$. As amostras das duas regiões foram fixadas em glutaraldeído 2,5\% em tampão fosfato $0,1 \mathrm{M} \mathrm{pH} 7,4$ por 24 horas a $4^{\circ} \mathrm{C}$. Após a fixação, os fragmentos foram lavados com uma solução salina tamponada e pós-fixados por duas horas com tetróxido de ósmio a 1\% em tampão fosfato. Em seguida, as amostras foram lavadas novamente com a mesma solução tampão e desidratadas em uma série crescente de etanol (50, 60, 70, 80, 90 e 100\%). Após a obtenção do ponto crítico de secagem, os fragmentos foram metalizados com ouro e fotografados em um microscópio eletrônico de varredura. A densidade média de folículos foi obtida a partir da contagem do número de folículos em quatro electromicrografias (folículos por $337.500 \mu \mathrm{m}^{2}$ ), por região e por ave.

O delineamento experimental utilizado foi inteiramente casualizado em esquema fatorial 3 x 2 (temperaturas de incubação x linhagens). Os dados foram submetidos à análise de variância e, em caso de diferença estatística significativa, as médias foram comparadas pelo teste de Tukey (5\%).

\section{DISCUSSÃO}

Não foi observada influência da temperatura de incubação e da linhagem na densidade folicular nas pterilosis femural (perna) e dorsopélvica (dorso) dos embriões D11 (Tabela 1). Aos 16 dias, entretanto, notase um aumento no número de folículos na região dorsal dos embriões incubados em temperatura quente $\left(38,8^{\circ} \mathrm{C}\right)$, acima da temperatura padrão, independente da linhagem estudada.

O aumento no número de folículos da região do dorso observada nos embriões D16 submetidos à temperatura quente permaneceu até o nascimento (D21). Entretanto, esse efeito não foi verificado para a densidade folicular da região femural nos embriões.

A temperatura ideal para a incubação de ovos de frangos foi motivo de muitas pesquisas durante um longo tempo, sendo que os melhores resultados encontrados sugerem a utilização de temperaturas variando entre $37,5^{\circ}$ e $37,8^{\circ} \mathrm{C}$ (DEUCHAR, 1952). Grande parte dos estudos da utilização de diferentes temperaturas na embriogênese envolveu taxa de desenvolvimento, e de metabolismo e anormalidades nos embriões provocadas por variações na temperatura. De modo geral, apregoa-se que pequenas variações da temperatura, acima ou abaixo do que é considerado padrão para a incubação $\left(37,8^{\circ} \mathrm{C}\right)$, aceleram ou retardam, respectivamente, o desenvolvimento do embrião (LACASTER \& JONES, 1988; LEANDRO et al., 2000). O que chama a atenção, no entanto, é que as variações térmicas impostas aos embriões, verificadas nos trabalhos encontrados na literatura, utilizam alterações cíclicas, por um período curto de tempo, de seis a 24 horas (ANDE \& WILSON, 1981; LEANDRO et al., 2000) e em fases específicas do desenvolvimento embrionário, geralmente após os 16 dias de incubação.

No presente trabalho, os tratamentos térmicos impostos aos embriões foram empregados a partir de períodos precoces de desenvolvimento ( $6^{\underline{0}}$ dia), período que coincide com a maturação do eixo hipotálamo-hipófise-tireoide e com o início da condensação de células na região da derme, que formarão as células germinativas da pena.

As variações de temperatura empregadas no presente estudo, acima ou abaixo da temperatura controle, não alteraram a densidade folicular dos embriões até o D11. Porém, após dez dias de estresse por calor crônico, os embriões apresentaram um aumento na densidade folicular na região dorsal, devido a esse aumento de temperatura, sendo que esta diferença permaneceu até o nascimento. Estes resultados sugerem uma maior sensibilidade desta região a altas temperaturas durante a incubação, talvez porque este aumento ocorreu coincidentemente no mesmo período em que se inicia a formação das células germinativas das penas na pterilosis dorsal $\left(6^{\circ}\right)$. Podese inferir também que a alta temperatura empregada na incubação a partir do sexto dia teve menor efeito sobre a formação inicial do folículo na região da perna, medida por meio da densidade folicular, uma vez que a formação do gérmen da pena inicia-se no período que antecedeu o tratamento térmico (5ํ dia de incubação).

Nas aves, as penas crescem em diferentes velocidades, demonstrando existir uma hierarquia na sua 
Tabela 1 - Valores médios de densidade folicular (folículos por 337,5 $\mu \mathrm{m}^{2}$ ) da porção medial da região dorsopélvica (dorso) e femural (perna) de embriões com 11 e 16 dias de incubação e neonatos de frangos de corte de diferentes genótipos submetidos a diferentes temperaturas de incubação.

\begin{tabular}{|c|c|c|c|c|c|c|}
\hline \multirow{2}{*}{ Tratamentos } & \multicolumn{2}{|c|}{---------11 dias---------- } & \multicolumn{2}{|c|}{---------16 dias--------- } & \multicolumn{2}{|c|}{---------21 dias---------- } \\
\hline & Perna & Dorso & Perna & Dorso & Perna & Dorso \\
\hline \multicolumn{7}{|c|}{ Temperatura incubação } \\
\hline $38,8^{\circ} \mathrm{C}$ (quente) & 51,10 & 57,4 & 43,60 & 48,5 a & 37,12 & $40,02 \mathrm{a}$ \\
\hline $37,8^{\circ} \mathrm{C}$ & 58,00 & 56,5 & 38,80 & $38,8 \mathrm{~b}$ & 29,16 & $32,75 \mathrm{~b}$ \\
\hline $36,8^{\circ} \mathrm{C}$ (fria) & 58,10 & 53,10 & 38,00 & 36,9 b & 28,54 & $33,24 \mathrm{~b}$ \\
\hline \multicolumn{7}{|l|}{ Linhagem } \\
\hline ISA Label & 55,27 & 55,26 & 39,73 & 41,53 & 32,15 & 34,20 \\
\hline Cobb & 56,40 & 56,53 & 40,57 & 41,26 & 30,85 & 35,67 \\
\hline \multicolumn{7}{|c|}{ ANOVA, valores de $\mathrm{P}$} \\
\hline Temperatura (TP) & 0,150 & 0,520 & 0,100 & 0,01 & 0,55 & 0,056 \\
\hline Linhagem (LI) & 0,710 & 0,800 & 0,720 & 0,88 & 0,32 & 0,740 \\
\hline TP $\times$ LI & 0,800 & 0,720 & 0,570 & 0,14 & 0,42 & 0,160 \\
\hline $\mathrm{CV} \%$ & 16,05 & 15,84 & 13,78 & 16,84 & 15,45 & 17,32 \\
\hline
\end{tabular}

Médias seguidas de letras diferentes (a,b) em uma mesma coluna, dentro de cada fator, diferem entre si pelo teste de Tukey (5\%).

formação e uma diferença na atividade dos folículos. Por exemplo, as penas levam aproximadamente quatro semanas para cobrirem a região dorsal e peitoral, aproximadamente cinco semanas para cobrir a região do pescoço, abdômen e seis semanas, para cobrirem a região da perna (FURLAN \& MACARI, 2002). Da mesma forma, na embriogênese, a formação das estruturas que comporão a pena seguem padrões distintos de desenvolvimento, que não seguem necessariamente o padrão pós-natal. O que chama a atenção, no entanto, é que, embora a temperatura tenha promovido uma alteração na densidade folicular na região dorsopélvica, pelo aumento no número de folículos por área avaliada, a morfogênese desta estrutura não foi alterada, mantendo o mesmo padrão de desenvolvimento, independente da temperatura de criação ou mesmo da linhagem. Portanto, o uso de de temperaturas mais elevadas pode ter reflexo na densidade folicular, cabendo verificar se esta mudança de temperatura de incubação pode promover outros efeitos na embriogênese.

$\mathrm{O}$ crescimento total do gérmen da pena (Figura 1 A- F) acontece até aproximadamente 12 dias. No oitavo dia de idade, pode ser observada uma organização das células na derme, formando um adensamento semelhante a feixes (Figura $1 \mathrm{~B}$ ).

A partir do $10^{\circ}$ dia de incubação, as células da derme, na base do gérmen da pena, começam um processo de adensamento em direção à hipoderme (Figura 1C e D). A divisão celular (mitose), que antes empurrava as células formadas na derme para a superfície da pele, devido a sua rápida proliferação, agora segue em direção a região proximal. A base não é o único sítio de crescimento, sendo que a mitose também pode ser vista nas células intermediárias. Começa a partir daí o processo de invaginação da epiderme.

No $11^{\circ}$ e $12^{\circ}$ dia de incubação, diversos germens da pena já invaginam para a camada papilar da derme (Figura 1 E e F). Como a invaginação e o crescimento das demais estruturas continuam, existe a formação de um tubo estreito e profundo, onde as células que compunham a gérmen da pena ficam mais densas, achatadas, com difícil visualização do núcleo. Estas células ocuparão parte mais profunda do folículo, formando a papila. Um corte transversal da papila mostra a presença de diferentes camadas de células. A mais externa das camadas é formada por um conjunto de células cubóides, chamadas de camada radiogênica. A partir destas células serão formadas as bárbulas e as barbículas. Na parte central da papila, está localizada a polpa e também pode ser vista a vascularização do folículo

Aos 14 dias as penas projetam-se acima da pele, porém, os folículos ainda não estão ligados à respectiva musculatura, o que só acontecerá próximo aos 16 dias (Figura 2 A-E). A musculatura da pena pode ser dividida em três grupos: (1) músculo eretor, que liga a porção mais superficial do folículo à porção próxima da papila do folículo anterior a ele; (2) músculo 


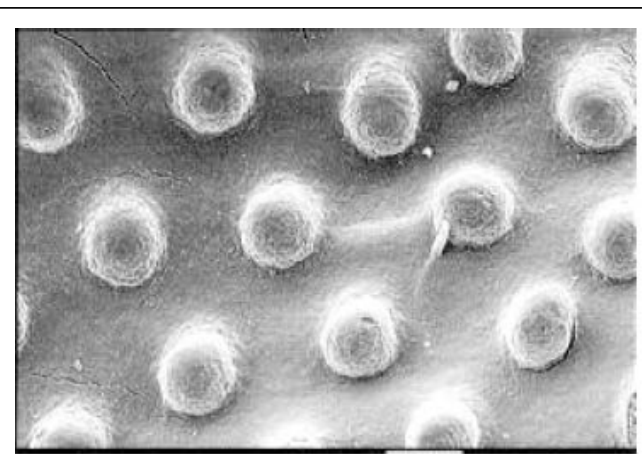

A

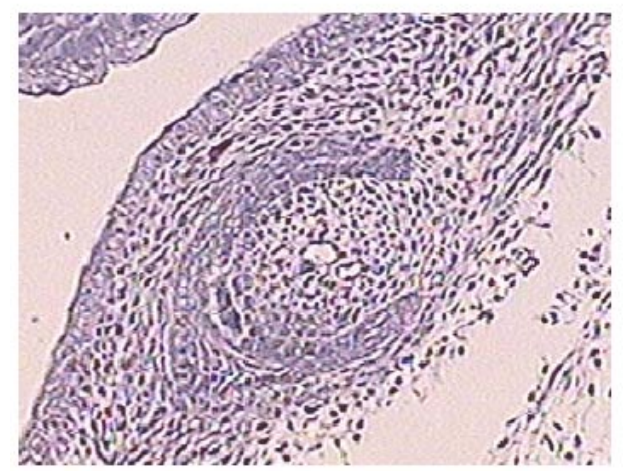

C

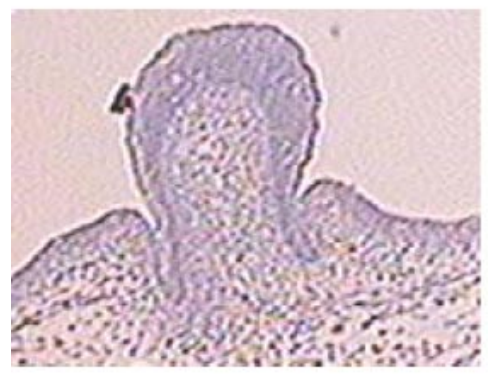

E

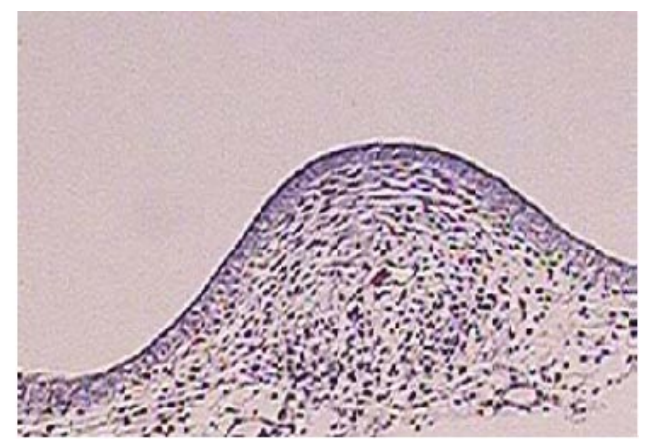

B

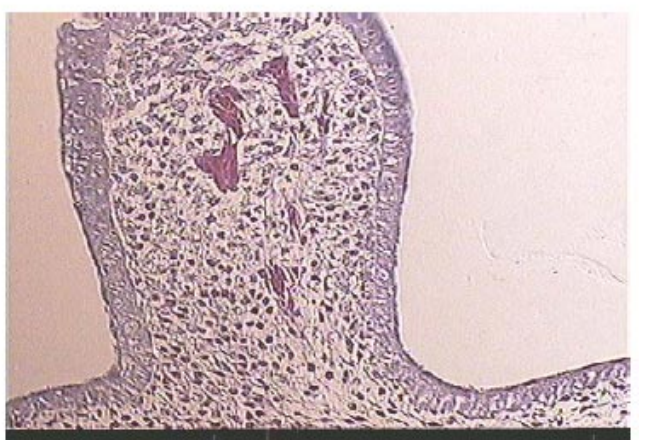

D

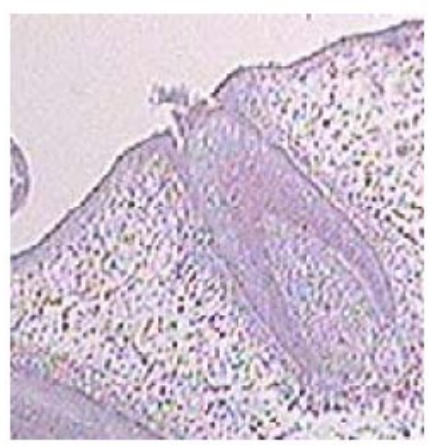

F

Figura 1 - Eletromicrografia de varredura (A) e corte transverso em microscopia de luz (B-F) da superfície da epiderme da pterilosis dorsopélvica (dorso) de embriões de frangos de corte da linhagem Cobb no $8^{\circ}$ e no $12^{\circ}$ dia de incubação, com alta temperatura $\left(38,8^{\circ} \mathrm{C}\right)$. A: dorso de embrião no $10^{\circ}$ dia. B: $8^{\circ}$ dia. C: $10^{\circ}$ dia. D: $10^{\circ}$ dia. E: $11^{\circ}$ dia. F: 12ํㅡㄹ. (Tiacrômio de Massom, 60X e 40X)

depressor, que liga a porção mais superficial do folículo à porção próxima da papila do folículo posterior a ele e (3) músculo retrátil, que liga a porção superficial do folículo anterior ao posterior.

Neste estágio inicial, que consiste no período de formação do gérmen, descrito e visto acima, até a formação da papila, as penas apresentaram um mesmo crescimento cronológico entre as linhagens estudadas.

\section{CONCLUSÕES}

Os resultados obtidos neste estudo são indicativos de que a temperatura de incubação acima da recomendada $\left(38,8^{\circ} \mathrm{C}\right)$ pode promover alterações na densidade folicular na pterilosis dorsopélvica, resultando em aumento no número de folículos nesta região. Embora a alta temperatura de incubação afete o 


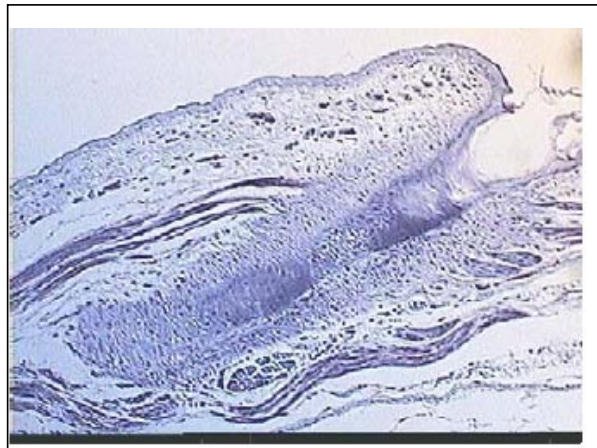

A

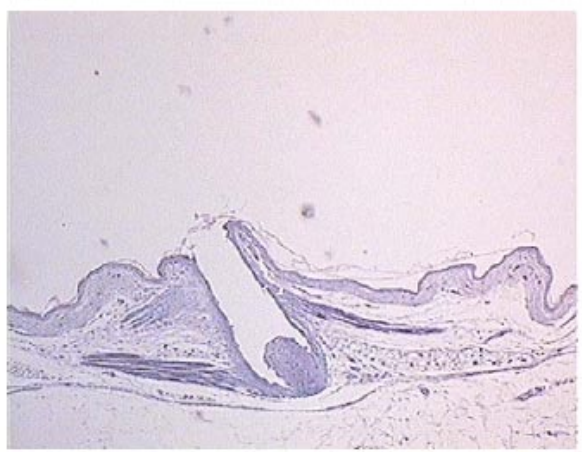

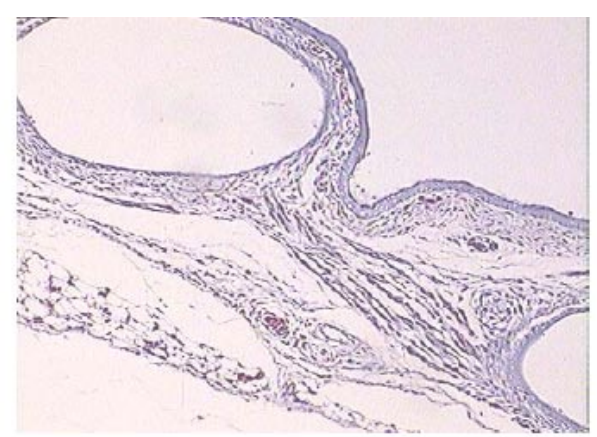

B

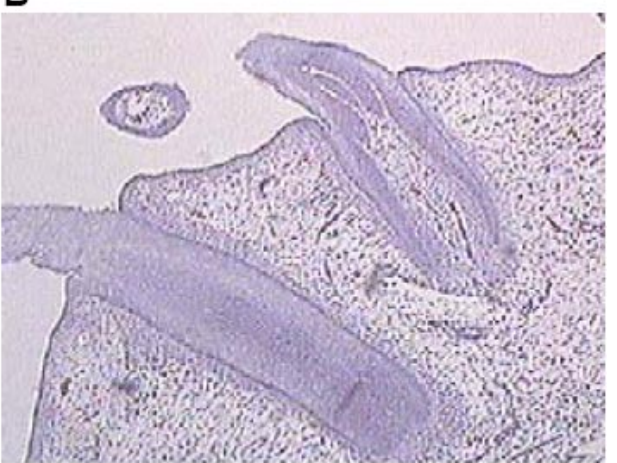

D

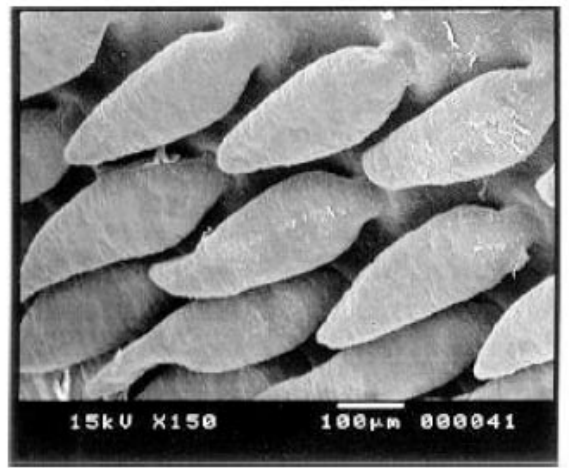

E

Figura 2 - Corte transverso em microscopia de luz (A-D) e Eletromicrografia de varredura (E) da superfície da epiderme da região dorsal (dorso) de embriões da linhagem Cobb aos 16 dias de incubação, com temperaturas acima da padrão. A e C: detalhe do folículo com respectivo músculo eretor. B: folículos ligados pela musculatura retrátil. D: projeção das penas. E: vista superficial do empenamento. Figura A - C: Tricrômio de Massom, 60X e 40X.

número de folículos, sua morfogênese é inalterada pela temperatura. Não existe variação no desenvolvimento folicular entre as linhagens avaliadas.

\section{FONTES DE AQUISIÇÃO}

${ }^{1}$ Mod. IP600 da PREMIUM ECOLÓGICA LTDA - Av. Henfil, 365, Belo Horizonte, Minas Gerais.

${ }^{2}$ Modelo Joel JSM 25 SII ${ }^{\circ}$

${ }^{3}$ Abbott Diagnistics Division, Antewerp, Bélgica.

${ }^{4}$ Amersham International, Inglaterra.

\section{REFERÊNCIAS}

ANDE, T.B.; WILSON, H.R. Hatchability of chicken embryos exposed to acute high temperature stress at various ages. Poultry Science, v.60, p.1561-1566, 1981.

BAROTT, H.G. Effects of temperature, humity, and other factors on hatch of hen's eggs and on energy metabolism of chicks embryo. U.S. Department of Agriculture Technical Bulletin, v.553, p.13-45, 1937.

CHRISTENSEN, V.L. et al. Influence of diet mediated maternal thyroid alterations on hatchability and metabolism 
of turkey embryos. Poultry Science, v.70, p.1594-1601, 1991.

DECUYPERE, E.; MICHELS, H. Incubation temperature as a management tool: a review. World's Poultry Science, v.48, p.28-38, 1992.

DECUYPERE, E. et al. Thyroid hormone before and during the hatching process in chickens. Effects of low temperature and iopanoic-acid treatment. Annales d'endocrinology, v.42, p.75-76, 1981.

DEEB, N.; CAHANER, A. The effects of naked neck genotypes, ambient temperature, and feeding status and their interactions on body temperature and performance of broilers. Poultry Science, v.78, p.1341-1346, 1999.

DEUCHAR, E. The effect of high temperature shock on early morphogenesis in the chick embryo. Journal of Anatomy, v.80, p.443-459, 1952.

FURLAN, R.L.; MACARI, M. Termoregulação. In.: MACARI, M. et al. (Ed.). Fisiologia aviária aplicada a frangos de corte. 2.ed. Jaboticabal: FUNEP, 2002. p.209-230.

GIACHETTO, P.F. Mecanismos hormonais do ganho compensatório e composição de carcaça em frangos de corte submetidos a restrição alimentar com diferentes níveis energéticos. 1998. 98f. Dissertação (Mestrado em Zootecnia)-Curso de Pós-graduação em Zootecnia, Faculdade de Ciências Agrárias e Veterinárias, Campus de Jaboticabal, UNESP.

LANCASTER, F.M.; JONES, D.R. Cooling of broiler hatching eggs during incubation. British Poultry Science, v.29, p.597-604, 1988.
LAWRENCE, T.L.J.; FOWLER, V.R. Hormonal, genetic and immunological influences on growth. In: LAWRENCE, T.L.J.; FOWLER, V.R. (Ed.). Growth of farm animals. New York: CAB INTERNATIONAL, 1997. p.102-149.

LEANDRO, N.S.M. et al. Incubabilidade e qualidade de pintos de ovos de matrizes de frangos de corte submetidos estresse de temperatura. Revista Brasileira de Ciência Avícola, v.2, p.39-44, 2000 .

OCKLEFORD, E.M. et al. Changes in plasma iodohormone concentrations during the day before hatching in Gallus domesticus. Compendium of Biochemistry and Physiology, v.75 ${ }^{\mathrm{A}}$, p.139-140, 1983.

SPERMAN, R.I.C. Body temperature and thermoregulation. In: BELL, D.J.; FREEMAN, B.M. Physiology and biochemistry of domestic fowl. London, 1971. V.2, p.11151151.

THOMMES, R. Ontogenesis of thyroid function and regulation in the developing chick embryo. Journal of Experimental Zoology Supplement, v.27, p.273-279, 1987.

TONA, K. et al. Effects of storange time on incubating egg gás pressure, thyroid hormones, and corticosterone levels in embryos and on their hatching parameters. Poultry Science, v.82, p.840-845, 2003.

TULlET, S.G. Science and art of incubation. Poultry Science, v.69, p.1-15, 1990. 